\title{
The rapid transit system for patients with fractures of proximal femur
}

\author{
J M SIKORSKI, N J DAVIS, J SENIOR
}

\begin{abstract}
The rapid transit system for patients with fractures of the proximal femur consists of immediate internal fixation or replacement of the fractured bone under spinal anaesthesia, without any sedation. Patients are mobilised within hours of surgery and sent home as soon as they can walk. They are supervised at home by both an experienced physiotherapist and a visiting nurse.

Sixty nine patients admitted to a metropolitan teaching hospital were considered for the system and 50 were accepted. Their age distribution and level of general ill health were comparable with those in other series. The rapid transit system resulted in $90 \%$ of patients accepted being discharged to their homes within the first five days, with a lower morbidity and a mortality at three months of $7 \%$.

Using the rapid transit system rehabilitation in the original environment is difficult only if the patient lives alone, and even then temporary support is often enough to allow them to return home.
\end{abstract}

\section{Introduction}

The elderly patient with a fracture of the proximal femur presents a complex series of medical and social problems.' The net result is

\footnotetext{
University Department of Surgery, Greenslopes Hospital, Greenslopes, Queensland, Australia

J M SIKORSKI, MD, FRCS, professor of orthopaedic surgery

Sir Charles Gairdner Hospital, Perth, Western Australia

N J DAVIS, MB, FFRACS, head of department of anaesthesia and intensive care J SENIOR, MCSP, ONC, deputy chief physiotherapist

Correspondence to: Professor J M Sikorski.
}

that such patients suffer high morbidity ${ }^{2}$ and mortality. ${ }^{3}$ Because these fractures are common they are a large drain on hospital resources. Their incidence is increasing, ${ }^{45}$ so that the problem is set to get worse.

The fractures themselves present a series of technical challenges which have now been largely overcome, to the extent that the patients can usually resume a basic level of mobility immediately after surgical reconstruction. Nevertheless, the injury and its sequelae do result in a reduction of the patients' mobility grading, ${ }^{6}$ and in a population whose independence is already threatened this deterioration in mobility is potentially serious. In addition to the mechanical problems of the hip fracture, these patients commonly suffer from other disorders, and often several serious chronic diseases coexist. Once the fracture has occurred then the resulting immobility causes further problems with a risk of urinary retention, incontinence, hypostatic pneumonia, and pressure sores. To this already serious picture are added the more or less inevitable consequences of treatment. Analgesics, hypnotics, and anaesthetic agents may sedate and confuse.

Investigations may disclose unsuspected disorders which generate further investigations and courses of treatment, all of which have risks and side effects. In addition, both treatment and investigations take time, a resource which is running out for some patients. There is a real risk that while the patients are being processed by the medical mill the social fabric of their home existence is disintegrating. Their friends forget them and their families decide to put them into an institution. If they are already in a nursing home then their bed may be reallocated. If they have pets these may be destroyed. Within a few days there may be nothing of their former lives for them to return to.

We believe that this setting of potential disaster is the result of a confused and profligate approach to the problem. This interpretation is supported by the finding that hospital mortality is actually increasing with time and presumably with technological advance. In one Norwegian hospital mortality among inpatients with fractures of the proximal femur was $4 \%$ during $1948-57$ and had increased to $14 \%$ by $1961-70{ }^{7}$ We contend that this trend can be reversed, but 
only by challenging some of the assumptions on which current treatment relies. In the case of patients with fractures of the proximal femur we suggest, firstly, that the primary problem is the mechanical failure of bone and that all other considerations are secondary to it: there is now a satisfactory, immediate, solution to this problem; secondly, that in the vast majority of cases these patients do not need to stay in hospital beyond the operative and immediate postoperative period; and, thirdly, that hospital based investigations and treatment of these patients are often counterproductive.

We present a new approach to the treatment of elderly patients with fractures of the proximal femur, the theme of which is rapid surgical reconstruction with minimal disturbance to the patient, followed by rehabilitation at home. It is called the rapid transit system.

\section{Patients and methods}

\section{CONCEPT}

The philosophy behind the rapid transit system was that a patient with a fracture of the proximal femur requires that the fracture should be dealt with as quickly as possible, with a high degree of technical skill and that he or she should be returned home as soon as treatment of a highly sophisticated nature is no longer needed.

\section{PATIENT SELECTION}

We considered for inclusion in the scheme all patients with established (or imminent, premalignant) fractures of the femoral neck or intertrochanteric region of the femur who presented to a large metropolitan teaching hospital when one of us (JMS) was the duty orthopaedic surgeon. The scheme covered 1982, 1983, and part of 1984 and was closed when 50 patients had been accepted and treated.

\section{PATIENT EXCLUSIONS}

Patients were rejected as unsuitable on five grounds: medical-if there was any other medical or surgical problem which, of itself, required hospitalisation (this did not include disorders which could be treated on an outpatient basis); technical-if the fracture was so unstable that the patient could not be expected to bear weight on the leg after internal fixation; distance-if the patient lived at, or was going to return to, a residence more than $25 \mathrm{~km}$ ( $15^{1 / 2}$ miles) away from the parent hospital (adequate support could not be arranged and supervised at distances greater than this); domestic-if living alone, being mentally or physically incompetent or unreliable, or not having basic domestic facilities such as hot running water, an inside toilet, and a telephone; and refusal-if the patient refused to return home or the relatives or attendants refused to have the patient back.

\section{INITIAL PATIENT ASSESSMENT}

The emergency department of the hospital concerned was notified of the inception of the scheme and the principles governing it. The staff were asked to cooperate by notifying the orthopaedic surgeon on call immediately a patient arrived with the signs and symptoms of a proximal femoral fracture. They were also instructed not to give any analgesics or initiate any complex investigations (see below).

Patients were assessed in the emergency department as soon as possible by JMS, who confirmed the diagnosis, initiated the basic investigations, and decided whether the fracture could be stabilised adequately. Once the patient was accepted on technical grounds the anaesthetist (NJD) and the physiotherapist (JS) were summoned. The anaesthetist carried out a routine clinical assessment. The decision was made whether the patient was suitable for spinal anaesthesia and whether there was any other major disorder which of itself required prolonged hospitalisation. Once the patient was accepted medically the operating suite was notified.

Routine investigations were strictly limited. All patients had their haemoglobin concentration estimated and blood group analysed, and two units of blood were cross matched. If there was a clinical indication these were supplemented by chest radiography, electrocardiography, and other biochemical tests, but these were not performed routinely.

The third member of the team was a senior orthopaedically trained physiotherapist. Her initial role was $(a)$ to explain to the patient, friends, relatives, or nursing home staff the nature of the scheme and get their consent and support; $(b)$ to evaluate the suitability of the home, which invariably meant that she had to visit the home; $(c)$ to provide or arrange to have installed required aids; and $(d)$ to inform the home nursing service and arrange for regular visits by the service and to organise other necessary help, such as meals on wheels.

\section{SURGERY AND POSTOPERATIVE PHASE}

Once the patient had been assessed and deemed suitable for the scheme, surgery was performed as soon as possible. Pain was controlled before and after surgery by a combination of non-narcotic analgesics and femoral and lateral cutaneous nerve blocks with $0.5 \%$ bupivacaine. Drugs with sedative properties-whether analgesic, hypnotic, or tranquilliser-were strictly avoided.

All surgery was performed by JMS. A spinal anaesthetic was used by preference, and in 36 cases this was performed satisfactorily; in 14 a general anaesthetic was administered. In six cases an attempt at spinal anaesthesia failed, one patient requesting a general anaesthetic. The duration of the operation, from introduction or induction of anaesthesia to skin closure, was less than 60 minutes in all cases. Each patient routinely had two units of blood transfused in the perioperative phase and the infusion apparatus removed immediately on completion. Short term (three dose) antibiotic prophylaxis was given. Two closed suction drains were used. Intertrochanteric fractures, malignant prefracture lesions, and undisplaced subcapital fractures were fixed internally with a Richards compression screw and plate system. Displaced subcapital fractures were dealt with using an uncemented Thompson hemiarthroplasty, introduced through an anterolateral (McKee) approach. In some patients the wound was infiltrated with $0.5 \%$ bupivacaine at the end of the operation.

Patients were got out of bed, fully weight bearing, as soon as possible. If the operation was in the morning then an attempt was made four to six hours later. If the operation was later in the day they were left in bed until the next morning. On the morning of the first postoperative day the patient was reassessed clinically. If there were no untoward respiratory or cardiovascular problems and the patient could walk a few steps with a walking frame arrangements were made for immediate discharge. If there was cause for concern, either because of a systemic disturbance or because of inertia, the patient was kept in for a further day and the assessment repeated the next day. Drains were removed in hospital, either immediately before discharge or after 48 hours, whichever was the longer. Non-narcotic analgesics were prescribed on a regular basis and a supply was provided for home use. Before discharge from hospital lines of communication were established between the patient, the physiotherapist, and the surgeon. The patient or his or her attendants were given the home and work telephone numbers of the physiotherapist and surgeon and told to contact either if any problems occurred.

\section{HOME REHABILITATION}

The patient was visited at home daily by the physiotherapist, until adequately mobile. A home nurse visited every day, and on rare occasions twice a day, to help with dressings and bathing or showering. A home help, meals on wheels, occupational therapist, social worker, and other agencies participated, as thought appropriate. All these services were withdrawn as soon as they were no longer needed. All the patients were visited at least once by the orthopaedic surgeon, usually between the third and fifth postoperative days. Routine outpatient appointments were not made, but patients could come to the outpatient clinic if a problem declared itself.

\section{COMPARATIVE FIGURES}

For comparison we present figures from the 1981 annual audit, details of which have been described ${ }^{\times}$and which cover patients admitted to the same service. In 1981 the rapid transit system had not started. Later figures were not used because the influence of the system had spread through the hospital and parts of it had been adopted by other surgeons.

\section{Results}

\section{PATIENT CHARACTERISTICS}

Sixty nine patients were considered for the scheme, and $50(72 \%)$ of these were accepted. There were 48 women and 21 men. The overall mean age at 
presentation was $76.8(\mathrm{SD} \mathrm{13.0)}$ years (fig 1). Most of the patients were in the 70-90 year age group, the $80-90$ year age group being the most heavily represented. Forty five patients underwent screw plate fixation of the fracture and 24 hemiarthroplasty. When the accepted and rejected groups were compared (table I) they were similar in age, sex, and distribution of operative procedures.

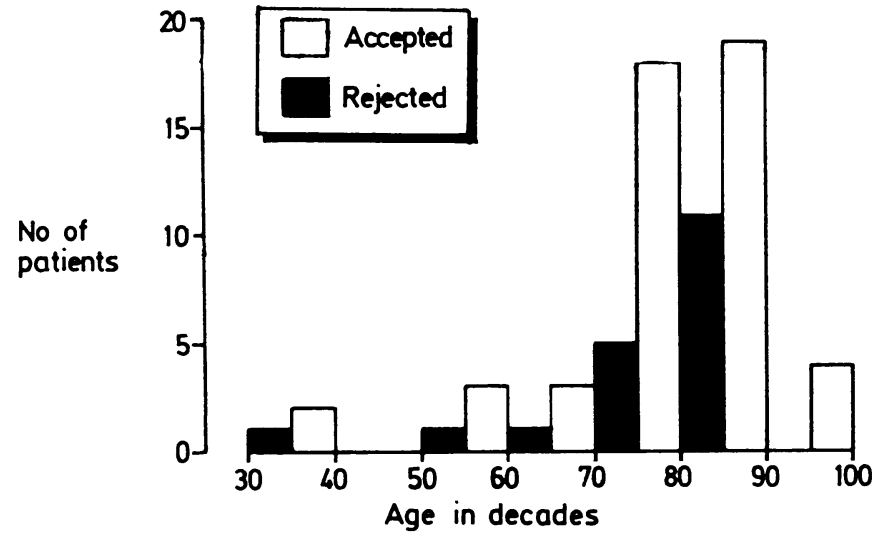

FIG 1-Age distribution of all patients considered for rapid transit system.

TABLE I-Details of patients accepted for and rejected from treatment by rapid transit system

\begin{tabular}{lcc}
\hline & Patients accepted & Patients rejected \\
\hline No & 50 & 19 \\
Mean age in years (SD) & $76 \cdot 2(13 \cdot 0)$ & $77 \cdot 3(14 \cdot 6)$ \\
No (\%) women & $36(72)$ & $12(63)$ \\
No treated by hemiarthroplasty & 17 & 7 \\
No treated by screw plate & 33 & 12 \\
Mean hospital stay (days) & $3 \cdot 0$ & $10 \cdot 5$
\end{tabular}

Forty of the accepted patients had another major disease or disorder currently active, as well as the femoral fracture (table II). Seven of these patients had three different systems affected in addition to the hip problem.

TABLE II -Diseases and disorders present on admission in patients accepted into rapid transit system

\begin{tabular}{lc|lc}
\hline & $\begin{array}{c}\text { No (\%) of } \\
\text { patients }\end{array}$ & & $\begin{array}{c}\text { No (\%) of } \\
\text { patients }\end{array}$ \\
Malignant disease & $11(22)$ & Alcoholism & $4(8)$ \\
Cardiovascular & $14(28)$ & Psychiatric & $12(24)$ \\
Respiratory & $7(14)$ & Other musculoskeletal & $11(22)$ \\
Urinary & $3(6)$ & Chronic neurological & $5(10)$ \\
Metabolic & $5(10)$ & Three or more of above & $7(14)$ \\
\hline
\end{tabular}

\section{REASONS FOR PATIENT REJECTION}

In 13 of the 19 patients rejected from the scheme the principal reason was the presence of another medical or surgical condition which of itself justified hospital treatment or monitoring. They included two patients who were receiving anticoagulants at the time of the fracture. In three cases the patients' attendants refused to have them back and demanded alternative placement. In one case the home environment was completely unsuitable and beyond redemption. One patient lived too far away from the hospital, and one fracture was so comminuted that it was thought wiser to mobilise the patient under close supervision.

RESPONSE OF PATIENTS, RELATIVES, FRIENDS, NURSING HOME STAFF, AND DOCTORS

Overall the degree of cooperation received was extremely high, and in most cases the scheme was met with great enthusiasm; the need for hospital based rehabilitation was, however, a matter of dispute.

\section{DURATION OF HOSPITALISATION}

The mean duration of stay in hospital was three nights for the patients accepted into the scheme and 10.5 nights for those patients rejected. Nineteen $(38 \%)$ of the patients accepted spent one night or less in hospital (fig 2), and 45 (90\%) had been discharged by the sixth day. There were four patients whom we regarded as failures. In one we misjudged the level of family support that we could mobilise, and in the other three cases the patients were too inert to manage alone at home. The 1981 audit showed a mean duration of stay in the orthopaedic wards of $17 \cdot 3$ (SD 13.9) days.

All our failures were among patients who had been living at home. One patient died in hospital without being discharged. She was a young woman with carcinomatosis who had superior vena caval obstruction. She died of a cerebral haemorrhage in the postoperative phase, having been overanticoagulated.

Figure 3 illustrates the impact of the scheme, in respect of all the patients considered, as compared with the 1981 audit. Plainly the rapid transit

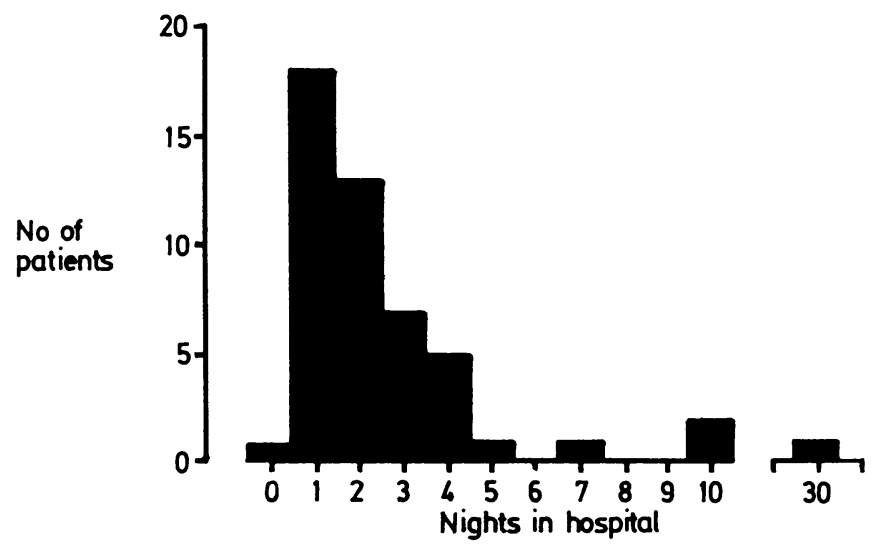

FIG 2-Duration of hospital stay of patients accepted into rapid transit system. One patient who died in hospital excluded from histogram.

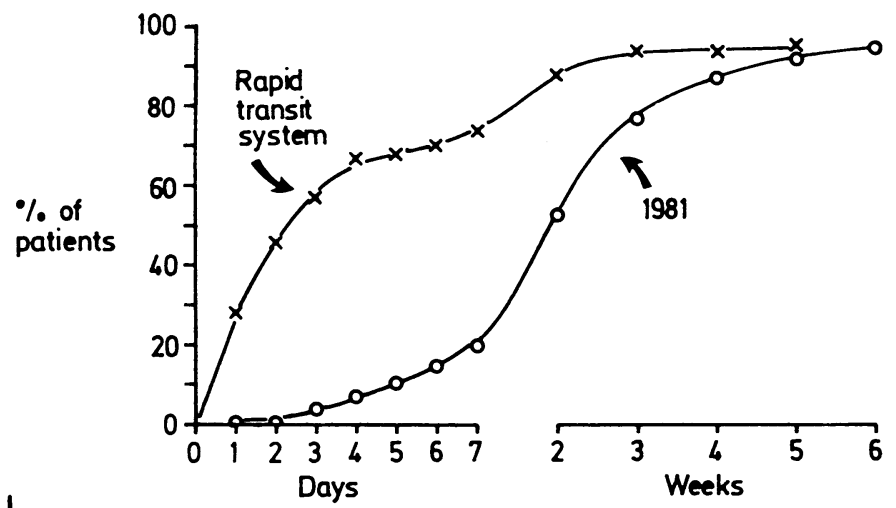

FIG 3 -Cumulative discharge rate of patients with fractures of proximal femur, expressed as percentage of all such patients admitted. Rapid transit system curve represents all 69 patients considered for scheme. I ower curve is that extracted from 1981 audit covering same institution (see text).

system had a profound influence on the group as a whole, hospitalisation being dramatically reduced. The area between the current series and the 1981 audit curve shows the percentage saving of bed days. This calculates out for the 69 patients in this trial as a saving of 479.6 bed days by the end of the fourth week. If this scheme had included 200 patients (which is the yearly admission rate for this hospital) then the saving would have been 1390 hospital bed days.

\section{COMPLICATIONS}

Complications were grouped into systemic, urinary, and technical (table III) and the results in these patients compared with statistics recorded in the 1981 audit (see Methods). The overall incidence of complications was lower in our series of patients, $26 \%$ developing some problem compared with $52 \%$ of the patients treated in 1981 . The differences were in the systemic and urinary categories. Technical problems were slightly more common in both the accepted and rejected groups. 
The four systemic problems that developed in patients accepted into the rapid transit system were: two deaths-one already described, and the second (five days after transfer to a nursing home) from respiratory failure in a chronic respiratory cripple; a pulmonary embolus which caused no long term problem; and anaemia in one patient, who had to be readmitted for transfusion.

\begin{tabular}{|c|c|c|c|c|c|}
\hline & \multicolumn{4}{|c|}{ Present study } & \multirow{3}{*}{$\begin{array}{c}\text { Incidence } \\
\text { recorded } \\
\text { in } \\
1981 \text { audi } \\
\%\end{array}$} \\
\hline & \multicolumn{2}{|c|}{ Patients accepted } & \multicolumn{2}{|c|}{ Patients rejected } & \\
\hline & No & ${ }^{\circ} \%$ & No & $o_{0}$ & \\
\hline Systemic & 4 & 8 & 5 & 26 & 23 \\
\hline Úrinary & 4 & 8 & 2 & 11 & 23 \\
\hline Technical & 6 & 12 & 2 & 11 & 6 \\
\hline
\end{tabular}

There were two major technical problems. In one comminuted intertrochanteric fracture the screw of the screw plate started to bend after two months and the hip was protected with a weight relieving calliper for a month. This man was readmitted for fitting of the calliper. The second patient fell again at home and had a recurrence of pain in her fixed hip. She was readmitted for three days for assessment but no definitive treatment was necessary.

In addition to the low systemic morbidity, there was also a noticeable reduction in urinary problems. Urinary retention especially was virtually abolished as a complication. We attribute this to not using narcotic analgesics. Only two patients had to be catheterised, and both had been given narcotics before admission.

\section{FATE OF DISCHARGED PATIENTS}

Patients entering the rapid transit system came from one of three sources (fig 4). Fifteen (30\%) were living alone at home, and of these only four were discharged back to their home without arranging for anyone to live in. Some of the patients for whom interim arrangements were made did ultimately resume living alone. Of the 11 who had to have some additional help, five were placed in an institution; while for six others arrangements were made so that they stayed either in their own home or with relatives. The patients living alone required the greatest amount of additional support and were the greatest challenge to the scheme.

Sixteen $(32 \%)$ patients were living at home and had some potential support available from a relative or friend who was living with them. Of these, 14 were sent back to their homes and managed well. Only one patient had to be placed in an institution. One of the patients who died had been admitted from home. Nineteen $(38 \%)$ came from institutions and all of them returned there. These patients were especially easy to deal with.

\section{OVERALL MORTALITY}

Nine of the 50 patients were known to have died. At one month the maximum mortality was $4 \%$ and by three months $7 \%$. Bevond that the figures were incomplete. Maximum mortality implies that all patients lost to follow up were assumed to have died.

\section{Discussion}

It would be iconoclastic to suggest that modern medicine has gone too far. We do not wish to get entangled in the argument about the distinction between aging and disease, which is fundamental to geriatric rehabilitation. We do not know how many of the ills that aging human flesh is heir to can be cured. Nevertheless, we are convinced that hospital is not the place for the elderly and that removing these people from their home environment is destructive. We are all too familiar with patients sitting around on orthopaedic wards, being slowly processed by a committee of medical and paramedical helpers, while family and friends lose interest.' Currently about half of these patients deteriorate in terms of their social independence. ${ }^{3}$

We know that some forms of medical treatment produce unacceptable side effects. Oversedation is a major problem, especially as it may result in a vicious circle of confusion, leading to further. sedation. It brings with it the risk of urinary incontinence and retention. Once these urinary problems are established the patients start on a course of catheterisations, impaired mobility, urinary infections, and possible secondary systemic disturbance, all of which may take a considerable period of time to sort out. Avoiding both narcotics and tranquillisers removed these problems in our series. The only patients who developed urinary problems while in hospital were those who had been given narcotics by doctors not acquainted with the scheme. Our embargo on sedative drugs included even apparently benign hypnotics such as the benzodiazepines, as they may give rise to a prolonged hangover and impairment of cerebral performance. ${ }^{9}$

The use of spinal anaesthesia, without any additional sedation, in preference to general anaesthesia is justified on several grounds. Firstly, it does not cause confusion. Secondly, that the patients are awake allows them to remain orientated in time and space. Thirdly, the spinal method provided the early postoperative analgesia. Fourthly, the patients avoided chest complications. Our favourable impressions of spinal anaesthesia have been confirmed by others.

\section{Living alone}

Initial

Returned

Relocated

4

\begin{tabular}{|c|c|c|c|}
\hline \multicolumn{2}{|c|}{$\frac{\text { Living at home with support }}{\text { (support arranged) }}$} & \multicolumn{2}{|c|}{$\frac{\text { Living in an institution }}{\text { (institutionalised ) }}$} \\
\hline Initial & 16 & Initial & 19 \\
\hline $\begin{array}{l}\text { Returned } \\
\text { Relocated } \\
\text { Died }\end{array}$ & $\begin{array}{r}14 \\
1 \\
1\end{array}$ & $\begin{array}{l}\text { Returned } \\
\text { Relocated }\end{array}$ & $\begin{array}{r}19 \\
0\end{array}$ \\
\hline
\end{tabular}

FIG 4-Origin and initial destination of patients passing through rapid transit system.

When used for total hip arthroplasty spinal anaesthesia results in less operative bleeding, ${ }^{10}$ better fibrinolytic function, ${ }^{11}$ and a lower incidence of thromboembolism. ${ }^{12}$ In patients with a proximal femoral fracture spinal anaesthesia results in lower mortality ${ }^{13}$ and avoids the hypoxia that occurs after general anaesthesia. ${ }^{14}$

The idea of allowing patients to convalesce and rehabilitate at home is not new. Day surgery is becoming increasingly common for elective general surgical ${ }^{15}$ and orthopaedic ${ }^{16}$ procedures and will certainly increase. The importance of such an approach for the elderly patient has been recognised after eye surgery ${ }^{17}$ and the comment made that the small risk of avoidable and treatable complications occurring at home is outweighed by the advantages of returning to familiar surroundings. Even after severe injury, such as femoral shaft fracture, home nursing has been used, though only in young children. ${ }^{18}$ We are simply extending the concept to another, large group.

Our initial plan was to supply these patients with extensive nursing and social support, but in fact this proved not to be necessary. In the vast majority a moderate level of general support was required for the first few days and was then reduced very rapidly. Daily visits by a district nurse and a physiotherapist occurred for the first five to seven days. Thereafter frequency diminished until after two to three weeks patients required no more than before their injury. Home help to do the cleaning and shopping was often needed and was provided by family, friends, neighbours, or a paid agency.

The advantages of the home rehabilitation programme are not just economic, though these are substantial. The patients are happier, suffer fewer complications, and rehabilitate faster. At home they dress themselves. They have substantial incentives to move around and thus perform their own physiotherapy. Switching on the television, getting a cup of tea, and letting the cat out all served as strong incentives to movement, the like of which is absent in hospital. A formal 20 minutes with a ward physio- 
therapist is no substitute. In addition, patients are able to establish or resume their own routines and are not regimented to sleep, wake, eat, and drink according to a fixed and often quite inappropriate schedule.

In conclusion our experience with the rapid transit system has convinced us that there are very great advantages in returning patients with fractures of the proximal femur to their home environments as early as possible. The benefits outweigh the risks. The scheme as practised in our unit has produced a group of patients who did not seem to suffer from the lack of prolonged hospital rehabilitation and who avoided some of the complications which are commonly associated with this injury. The patients themselves were pleased to return home. Although there were major economic gains, these were overshadowed by the medical and social advantages.

\section{References}

1 Anonymous. The old woman with a broken hip [Editorial]. Lancet 1982;ii:419-20 2 Sikorski JM, Millar AJ. Systemic disturbance from Thompson's arthroplasty. F Bone foint Surg
1977;59b:398-401.
3 Jensen JS, Bagger J. Long-term social prognosis after hip fractures. Acta Orthop Scand 1982;53:97-101.

4 Jensen JS, Tondetold E. A prognostic evaluation of the hospital resources required for the treatment of hip fractures. Acta Orihop Scand 1980;51:515-22.

5 Zetterberg C, Andersson GB. Fractures of the proximal end of the femur in Goteborg, Sweden, 1940-1979. Acta Orthop Scand 1982;53:419-26.

6 Miller CW. Survival and ambulation following hip fracture. 7 Bone foint Surg 1978;60A:930-4.

7 Dahl E. Mortality and life expectancy after hip fractures. Acta Orthop Scand 1980;51:163-70.

8 Sikorski JM, Mander J. Orthopaedic audit: a comprehensive system for inpatients. Health Sikorski JM, Mander J.
Trends 1984;16:30-3.

9 Cook PJ, Huggett A, Graham-Pole R, Savage IT, James IM. Hypnotic accumulation and hangover in elderly inpatients: a controlled double blind study of temazepam and nitrazepam. Br Med F 1983;286: 100-2.

10 Roberts JA. Failure patterns after total hip arthroplasty. Br Med $\mathcal{f}$ 1983;286:1899.

11 Modig J, Borg T, Bagge L, Saldeen T. Role of extradural and of general anaesthesia in fibrinolysis and coagulation after total hip replacement. Br f Anaesth 1983;55:625-9.

12 Modig J, Borg T, Karlstrom G, Maripuu E, Sahlstedt B. Thromboembolism after total hip replacement: role of epidural and general anesthesia. Anesth Analg 1983;62:174-80.

13 McLaren AD, Stockwell MC, Reid VT. Anaesthetic techniques for surgical correction of fractured neck of femur. Anaesthesia 1978;33:10-4.

14 McKenzie PJ, Wishart HY, Dewar KM, Gray I, Smith G. Comparison of the effects of spinal anaesthesia and general anaesthesia on postoperative oxygenation and perioperative mortality. Br 7 Anaesth 1980;52:49-53.

15 Burn JM. Responsible use of resources: day surgery. Br Med f 1983;286:492-3.

16 Haines JF, Thompson H. Short-stay surgery in orthopaedics. Health Trends 1982;14:73-4.

16 Haines JF, Thompson H. Short-stay surgery in
17 Fry EN. Day surgery. Br Med $\mathcal{F}$ 1983;286:894.

17 Fry EN. Day surgery. Br Med $\mathcal{A} 1983 ; 286: 894$.
18 Holmes SJK, Sedgewick DM, Scobie WG. Domiciliary gallows traction for femoral shaft Holmes SJK, Sedgewick DM, Scobie WG. Domiciliary gallows
fractures in young children. $\mathcal{F}$ Bone foint Surg 1983;65B:288-90.

(Accepted 7 November 1984

\title{
Communicable Diseases
}

\section{Deaths from measles in England and Wales, 1970-83}

\author{
C L MILLER
}

The annual number of deaths attributed to measles on death certificates fell from 39 in 1970 to 17 in 1983, but the ratio of deaths to measles notifications showed no declining trend over the period (table).

Deaths from measles in (a) previously normal and (b) previously abnormal persons, and deaths from subacute sclerosing panencephalitis 1970-83

\begin{tabular}{cccccc}
\hline Year & $\begin{array}{c}\text { Total } \\
\text { measles } \\
\text { deaths }\end{array}$ & $\begin{array}{c}\text { Ratio/10 000 } \\
\text { notifications }\end{array}$ & $\begin{array}{c}(a) \\
\text { Previously } \\
\text { normal } \\
\text { (No \%) }\end{array}$ & $\begin{array}{c}(b) \\
\text { Previously } \\
\text { abnormal }\end{array}$ & $\begin{array}{c}\text { Subacute } \\
\text { sclerosing } \\
\text { panencephalitis }\end{array}$ \\
\hline 1970 & 39 & 1.3 & $24(62)$ & 15 & 5 \\
1971 & 25 & 1.9 & $17(68)$ & 8 & 9 \\
1972 & 29 & 2.0 & $18(62)$ & 11 & 15 \\
1973 & 27 & 1.8 & $18(67)$ & 9 & 15 \\
1974 & 19 & 1.7 & $12(63)$ & 7 & 12 \\
1975 & 13 & 0.9 & $10(77)$ & 3 & 14 \\
1976 & 11 & 2.0 & $4(36)$ & 7 & 15 \\
1977 & 18 & 1.0 & $5(28)$ & 13 & 18 \\
1978 & 13 & 1.0 & $6(46)$ & 7 & 15 \\
1979 & 14 & 1.8 & $7(50)$ & 7 & 15 \\
1980 & 23 & 1.6 & $8(35)$ & 15 & 12 \\
1981 & 12 & 2.3 & $3(25)$ & 9 & 13 \\
1982 & 10 & 1.1 & $3(30)$ & 7 & 2 \\
1983 & 17 & 1.6 & $9(50)$ & 8 & 175 \\
\hline & 270 & 1.5 & $144(53)$ & 126 & \\
\hline
\end{tabular}

Epidemiological Research Laboratory, Public Health Laboratory Service, London NW9 5HT

C L MILLER, BCH, MFCM, senior epidemiologist

\section{Methods and results}

To establish the age, primary cause of death, and proportion associated with previous abnormalities, copies of death certificates were obtained from the Office of Population Censuses and Surveys for 270 deaths from measles and 175 from subacute sclerosing panencephalitis over the period. Where information on death certificates was inadequate or ambiguouś inquiries were made to the hospital or notifying doctor. No attempt was made to establish further clinical details, vaccination history, or social class.

The overall ratio of deaths to measles notifications was 1.5 per 10000 , but for children under 1 year it was 4.8 and for those aged 1-2 it was $2 \cdot 3$. Fifty-three per cent of the 270 deaths occurred in individuals with no pre-existing condition, and for these the proportion was highest (32/42) under 1 year and decreased with age. The converse was true for those previously abnormal: 31 of the 38 deaths over the age of 10 occurred in this group.

The most common primary cause of death at all ages was bronchopneumonia, followed by encephalitis and a combination of the two. In those previously normal $73 \%$ of deaths under the age of 2 and $45 \%$ from 2-9 were due to bronchopneumonia. Nearly twice as many children aged 2-9 died of encephalitis (28/78) than children under $2(11 / 59)$. Other causes included toxaemia from measles (12), cerebral thrombosis, rupture of lung, acute pericarditis, adrenal failure, and disseminated intravascular coagulation.

The pre-existing conditions in the 126 previously abnormal individuals included cerebral palsy (24), mental retardation (20), Down's syndrome (19) and various congenital abnormalities (22). There were nine children with immune deficiency or immunosuppression, and 19 aged 2-8 with lymphatic leukaemia, a number of them in remission.

Deaths from subacute sclerosing panencephalitis were few in 1970 and 1971 , probably because it was not widely diagnosed before 